\title{
Clozapine-related Sudden Pericarditis in a Patient Taking Long Acting Aripiprazole and Valproate: A Case Report
}

\author{
Domenico De Berardis ${ }^{1,2}$, Michele Fornaro ${ }^{3,4}$, Laura Orsolini ${ }^{3,5,6}$, Luigi Olivieri ${ }^{1}$, Francesco Nappi ${ }^{1}$, \\ Gabriella Rapini $^{1}$, Federica Vellante ${ }^{1,2}$, Cosimo Napoletano ${ }^{7}$, Nicola Serroni ${ }^{1}$, Massimo Di Giannantonio ${ }^{2}$ \\ ${ }^{1}$ National Health Service, Department of Mental Health, Psychiatric Service of Diagnosis and Treatment, Hospital "G. Mazzini", Teramo, \\ ${ }^{2}$ Department of Neurosciences and Imaging, University "G. d'Annunzio", Chieti, ${ }^{3}$ Polyedra Research Group, Teramo, Italy, ${ }^{4}$ New York Psychiatric \\ Institute, Columbia University, New York, NY, USA, ${ }^{5}$ School of Life and Medical Sciences, University of Hertfordshire, Hatfield, UK, ${ }^{6}$ Department \\ of Psychiatry and Neuropsychology, University of Maastricht, Maastricht, The Netherlands, ${ }^{7}$ Department of Cardiovascular, Hospital "G. \\ Mazzini", Teramo, Italy
}

\begin{abstract}
Clozapine may be associated with cardiovascular adverse effects including QTc prolongation and, more rarely, with myocarditis and pericarditis. Although rare, these latter cardiovascular adverse effects may be life-threatening and must be immediately recognized and treated. Several cases of clozapine related-pericarditis have been described and often it has a subtle and insidious onset with symptoms that may be often misdiagnosed with psychiatric manifestations (e.g. anxiety, panic or somatization) leading to a delayed correct diagnosis with potential fatal consequences. In the present report we describe the case of a 27-year-old girl with schizoaffective disorder taking long acting aripiprazole and valproate who developed a sudden onset clozapine-related pericarditis during titration phase that resolved with immediate clozapine discontinuation and indomethacin administration. We underline the importance of an early diagnosis of clozapine-related pericarditis and the need to have monitoring protocols to prevent this potentially fatal adverse effect especially when polypharmacy is administered to patients taking clozapine.
\end{abstract}

KEY WORDS: Clozapine; Pericarditis; Valproic acid; Polypharmacy; Drug monitoring.

\section{INTRODUCTION}

Even if clozapine represents the "gold standard" antipsychotic for treatment-resistant schizophrenia and other psychotic disorders, it may be associated with cardiovascular adverse effects ${ }^{1)}$ including QTc prolongation and, more rarely, with myocarditis and pericarditis. ${ }^{2)}$ Although rare, these latter cardiovascular adverse effects may be life-threatening and must be immediately recognized and treated. ${ }^{3)}$ Clozapine related-pericarditis may have a subtle and insidious onset and symptoms may include shortness of breath, heart palpitations, fatigue and chest pain. ${ }^{4)}$ These symptoms may be often misdiagnosed

Received: March 27, 2017 / Revised: May 2, 2017

Accepted: May 3, 2017

Address for correspondence: Domenico De Berardis, MD, PhD National Health Service, Department of Mental Health, Psychiatric Service of Diagnosis and Treatment, Hospital "G. Mazzini", Piazza Italia 1, 64100 Teramo, Italy

Tel: +39-0861429708, Fax: +39-0861429709

E-mail: domenico.deberardis@aslteramo.it

ORCID: https://orcid.org/0000-0003-4415-5058 with psychiatric manifestations (e.g., anxiety, panic or somatization) leading to a delayed correct diagnosis with potential fatal consequences. ${ }^{5}$ )

In the present case report we describe the case of a sudden onset clozapine-related pericarditis during titration phase in a patient taking long acting aripiprazole and valproate.

\section{CASE}

A 27-year-old girl was diagnosed with schizoaffective disorder at age of 19 years and previously treated with haloperidol and, after, risperidone and valproate with small clinical improvement and development of adverse side effect (i.e., parkinsonism). Risperidone was gradually tapered off and long-acting aripiprazole $400 \mathrm{mg}$ once monthly (OM) was added to her regimen with mild improvement and disappearance of parkinsonism.

However, she was voluntarily admitted in half October 2016 in psychiatric ward of Teramo (Italy) due to a clinical

(ㄷ) This is an Open-Access article distributed under the terms of the Creative Commons Attribution Non-Commercial License (http://creativecommons.org/licenses/by-nc/4.0) which permits unrestricted non-commercial use, distribution, and reproduction in any medium, provided the original work is properly cited. 


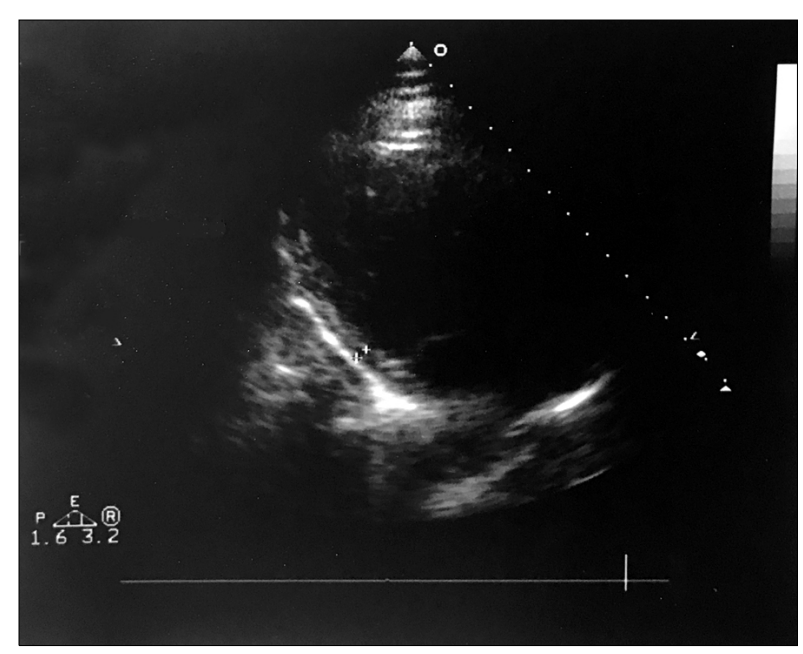

Fig. 1. Echocardiography documenting a mild pericardial effusion in the right ventricle without cardiac tamponade or myocardial dysfunction.

picture characterized by persistence of affective flattening, reduced ability to plan or carry out activities, mild agitation and moderate elevated/irritable mood in conjunction with persecutory and grandiosity delusions and moderate disorganization. She was taking long acting aripiprazole $400 \mathrm{mg} /$ day OM (last injection at the end of September), lorazepam $1 \mathrm{mg}$ once daily (OD) and valproate $500 \mathrm{mg}$ twice daily (BID).

We decided to add a low dose of clozapine (100 mg BID) jointly with other ongoing treatments. Before starting clozapine analysis of white blood cell count (WBC) and absolute neutrophil count (ANC) was evaluated and was within normal limits. Other routine blood analyses were normal (including B-type natriuretic peptide [BNP], troponin and C-reactive protein [CRP]) as well as electroencephalogram, electrocardiogram and echocardiography. Clozapine was initiated following drug data sheet and slowly titrated after six days up to $100 \mathrm{mg} /$ day, without significant side effects. At the eight day, following a routine monitoring based on a protocol developed by us from Ronaldson et al. ${ }^{6}$ for clozapine-related myocarditis, we found an increase of CRP $(30.03 \mathrm{mg} / \mathrm{L}$, range $0-5$ $\mathrm{mg} / \mathrm{L})$, troponin $(30.03 \mathrm{pg} / \mathrm{ml}$, range $0-14 \mathrm{pg} / \mathrm{ml})$ and creatinkinase (CPK, $455 \mathrm{U} / \mathrm{L}$, range 20-170 $455 \mathrm{U} / \mathrm{L})$. BNP was normal $(5.0 \mathrm{pg} / \mathrm{ml}$, cutoff $<14)$ as well as blood cell count. Electrocardiogram showed only a sinus tachycardia (121 bpm). However, the patient was almost asymptomatic and complained (only from the night before blood samples) of mild shortness of breath (that pa- tient attributed to "anxiety") and mild elevation in body temperature $\left(37^{\circ} \mathrm{C}\right)$. No other symptoms were reported. We immediately executed an echocardiography (Fig. 1) that documented an hyperkinetic cardiac activity with a preserved ventricular kinetic without dilatation. However, in the right ventricle, mild pericardial effusion was documented without cardiac tamponade or myocardial dysfunction, a clinical picture leading to the hypothesis of clozapine-related pericarditis.

Clozapine was immediately discontinued and, following cardiologist recommendation, she was initiated with indomethacin $50 \mathrm{mg}$ per oral BID, maintaining valproate $500 \mathrm{mg}$ BID. After five days a new blood routine showed a normalization of CRP, CPK and troponin. As well, a new echocardiography documented the reversal of pericarditis. The patient was after discharged with the addiction of quetiapine $50 \mathrm{mg}$.

The last observation was made in March 2017; the patient was taking long acting aripiprazole $400 \mathrm{mg} /$ day OM (last injection at the end of February), lorazepam $1 \mathrm{mg}$ OD, quetiapine $50 \mathrm{mg} /$ day and valproate $500 \mathrm{mg}$ BID without adverse effects and good improvement. WBC and ANC were within normal limits as well as electrocardiogram, CRP, CPK and troponin.

The patient provided informed consent to present this report.

\section{DISCUSSION}

To date, this was the first reported case of a clozapine-related pericarditis in a patient who was taking both long acting aripiprazole and valproate. In this case, the patient developed a sudden clozapine-related pericarditis which is mostly asymptomatic with mild pericardial effusion, at the end of $100 \mathrm{mg} /$ day titration phase, although a prompt diagnosis of mild pericardial effusion avoided cardiac tamponade complication. The clozapine-related pericarditis is a relatively uncommon adverse effect of this drug. We conducted a Medline search of publications from 1989 to 2017 and, using the keywords pericarditis and clozapine, we found 25 papers, mostly case reports, on this topic. There are several clinical presentations from mild-to-moderate shortness of breath and postural pleuritic-like chest pain to cardiac tamponade. ${ }^{7-9)}$ In the majority of reviewed cases, clozapine treatment was immediately discontinued, resulting in complete resolution of 
symptoms. ${ }^{4,10)}$ In some cases a clozapine rechallenge was tried, but this strategy is controversial as pericarditis may develop again, even it is not the rule..$^{11,12)}$

There is only one report that has investigated the long-acting aripiprazole/clozapine combination in a case of ultra-resistant schizophrenia without insurgence of adverse effects. ${ }^{13)}$ However, in our case, we cannot exclude that this combination may have contributed to cause the observed clozapine-related pericarditis. Moreover, even it has been suggested that valproate-clozapine association may cause eosinophilic effusion, ${ }^{14)}$ we excluded a role of valproate on the matter, because this latter was unaltered for years and any clinically significant pharmacokinetic interaction between these two drugs is likely to happen. ${ }^{15}$ However, it is worthy to note that, in most cases, antipsychotic and/or other psychotropic polypharmacy may increase the risk of clozapine-related pericarditis and myocarditis $^{2,16,17)}$ and, therefore, a greater attention must be the rule in such cases even in asymptomatic patients.

Clozapine-related myocarditis was also excluded since echocardiography, cardiac necrosis markers and brain natriuretic peptide were all negative. Clozapine was a definite causative agent (score of 9) according to the Naranjo probability scale, ${ }^{18)}$ which evaluates single-drug adverse events.

Therefore, we suggest that electrocardiogram, CRP, troponin $\mathrm{T}$, and cardiac ultrasound records should be considered before clozapine introduction and during its titration phase, especially in the case of concomitant treatments (such as, in this case, long-acting aripiprazole and valproate), even if the patients is relatively asymptomatic. This case underlines the importance of early diagnosis of clozapine-related pericarditis and the need to have monitoring protocols to prevent this potentially fatal adverse effect especially when polypharmacy is administered.

\section{REFERENCES}

1. Curto M, Girardi N, Lionetto L, Ciavarella GM, Ferracuti S, Baldessarini RJ. Systematic review of clozapine cardiotoxicity. Curr Psychiatry Rep 2016;18:68.

2. De Berardis D, Campanella D, Serroni N, Rapini G, Olivieri L, Fornaro $\mathrm{M}$, et al. Clozapine-related pericarditis during titration phase in a patient with resistant schizophrenia and concomitant valproate treatment: a case report. J Clin Psychopharmacol 2014,34:649-651.

3. De Berardis D, Serroni N, Campanella D, Olivieri L, Ferri F, Carano A, et al. Update on the adverse effects of clozapine: fo- cus on myocarditis. Curr Drug Saf 2012;7:55-62.

4. Paul I, Basavaraju V, Narayanaswamy JC, Math SB. Clozapineinduced pericarditis: an overlooked adverse effect. Clin Schizophr Relat Psychoses 2014;8:133-134.

5. Rathore S, Masani ND, Callaghan PO. Clozapine-induced effuso-constrictive pericarditis. Case report and review of the literature. Cardiology 2007;108:183-185.

6. Ronaldson KJ, Fitzgerald PB, McNeil JJ. Clozapine-induced myocarditis, a widely overlooked adverse reaction. Acta Psychiatr Scand 2015;132:231-240.

7. Markovic J, Momcilov-Popin T, Mitrovic D, Ivanovic-Kovacevic S, Sekuli S, Stojsic-Milosavljevic A. Clozapine-induced pericarditis. Afr J Psychiatry (Johannesbg) 2011;14:236-238.

8. Layland JJ, Liew D, Prior DL. Clozapine-induced cardiotoxicity: a clinical update. Med J Aust 2009;190:190-192.

9. Körtner K, Neuhaus AH, Schürer F, Dettling M. Eosinophilia indicating subclinical clozapine-induced pericarditis. J Clin Psychiatry 2007;68:1147-1148.

10. Prisco V, Monica P, Fiore G, Tridente A, La Rocca A, Catapano $\mathrm{F}$, et al. Brain natriuretic peptide as a biomarker of asymptomatic clozapine-related heart dysfunction: a criterion for a more cautious administration. Clin Schizophr Relat Psychoses 2016. doi: 10.3371/CSRP.PRMO.112316. [Epub ahead of print]

11. Crews MP, Dhillon GS, MacCabe JH. Clozapine rechallenge following clozapine-induced pericarditis. J Clin Psychiatry 2010;71:959-961.

12. Manu P, Sarpal D, Muir O, Kane JM, Correll CU. When can patients with potentially life-threatening adverse effects be rechallenged with clozapine? A systematic review of the published literature. Schizophr Res 2012;134:180-186.

13. Sepede G, Di lorio G, Spano MC, Lorusso M, Sarchione F, Santacroce $\mathrm{R}$, et al. A case of resistant schizophrenia successfully treated with clozapine/long-acting injectable aripiprazole combination. Clin Neuropharmacol 2016;39:322-324.

14. Fernández-Pérez R, Alvarez-Dobaño JM, Suárez-Antelo J, Codesido-Barcala R, Carballal-Calvo F, Arrojo-Romero M, et al. Eosinophilic pleural effusion associated with the addition of sodium valproate. JClin Psychopharmacol 2009;29:310-311.

15. Facciolà G, Avenoso A, Scordo MG, Madia AG, Ventimiglia A, Perucca E, et al. Small effects of valproic acid on the plasma concentrations of clozapine and its major metabolites in patients with schizophrenic or affective disorders. Ther Drug Monit 1999;21:341-345.

16. Presecki P, Grosić V, Silić A, Mihanović M. Infection or idiosyncratic reaction to antiepileptic drugs? Psychiatr Danub 2010;22:132-134.

17. Cadeddu G, Deidda A, Stochino ME, Velluti N, Burrai C, Del Zompo M. Clozapine toxicity due to a multiple drug interaction: a case report. J Med Case Rep 2015;9:77.

18. Naranjo CA, Busto U, Sellers EM, Sandor P, Ruiz I, Roberts EA, et al. A method for estimating the probability of adverse drug reactions. Clin Pharmacol Ther 1981;30:239-245. 